Tersedia online di: http://ejournal-balitbang.kkp.go.id/index.php/JP
e-mail.jurnalpari@gmail.com
JURNAL PARI
Volume 3 Nomor 2 Desember 2017
p-ISSN: 2502-0730
e-ISSN : 2549-0133

\title{
EVALUASI KOLABORASI PENELITI PADA JURNAL ILMIAH INDONESIAN AQUACULTURE JOURNAL 2011-2015
}

The Evaluation Of Researcher's Collaboration In Indonesian Aquaculture Journal 2011-2015

\section{ERNY PUSPA}

Pusat Riset Periklanan

Diterima tanggal : 10 Oktober 2017 diterima setelah perbaikan : 19 November 2017 disetujui terbit : 5 Desember 2017

\begin{abstract}
ABSTRAK
Kajian ini merupakan aplikasi hukum bibliometrika dalam bidang ilmu perpustakaan, dengan tujuan mengetahui kolaborasi dan produktivitas peneliti pada Indonesian Aquaculture Journal (IAJ). kajian menggunakan metode deskriftif, dengan menggunakan data publikasi Indonesian Aquaculture Journal tahun 2011-2015. Hasil evaluasi menunjukkan jumlah artikel pada IAJ 2011-2015 sebanyak 100 artikel dengan penulisan yang dilakukan secara kolaborasi sebanyak 92 artikel dan 8 artikel secara individual sedangkan untuk pola kepengarangan secara kolaborasi sebanyak 320 dan secara individu 8. Penulis paling produktif adalah Imron (11 artikel) dan diikuti oleh Ketut Mahardika (10 artikel). Adapun evaluasi rata-rata tingkat kolaborasi penulisan pada Indonesian Aquaculture Journal 2011-2015 sebesar 0,98 (98\%) menunjukkan angka ini merupakan kriteria hampir sempurna dalam kualitas penelitian karena hampir $100 \%$ penelitian dilakukan secara kolaborasi
\end{abstract}

KATA KUNCI : evaluasi, kolaborasi, Jurnal ilmiah , produtivitas

\section{ABSTRACT}

The study was an application of bibliometric in librarianship, which aim to know the collaboration and researcher's productivity in Indonesian Aquaculture Journal (IAJ). The study used a descriptive method, which the primary data obtained from Indonesian Aquaculture Journal publication since 2011 until 2015. The result showed that the articles of IAJ in 2011 until 2015 as much 100 articles with authors collaborative as much as 92 articles and 8 articles individually while for the pattern of collaborative authorship as much as 320 and individually 8 . The researchers whose actively productive were Imron (11 articles) followed by Ketut Mahardika (10 articles). The evaluaction of level rate in collaboration in Indonesian Aquaculture Journal since 2011-2015 as much 0,98 (98\%) showed that the criteria perfect in research quality because almost $100 \%$ the research done with collaboration.

KEYWORDS : evaluation, collaboration, scientific journal, productivity

Korespondesi penulis:

Gedung BRSDM II, JI. Pasir Putih II Ancol Timur Jakarta Utara

email: erny.puslitbangkan@gmail.com 


\section{PENDAHULUAN}

Pusat Riset Perikanan merupakan lembaga dibawah kementerian Kelautan dan Perikanan mempunyai tugas melakukan penelitian tentang Riset Perikanan. Sebagai wujud hasil penelitian institusi salah satunya dengan penerbitan jurnal penelitian dari lembaga tersebut. Pusat Riset Perikanan memiliki publikasi ilmiah seperti. Jurnal, prosiding, media dan bulletin sebagai wadah tulisan peneliti untuk menyalurkan hasil karyanya sehingga dapat dipublikasikan dan di akses masyarakat

Salah satu publikasi yang diterbitkan Pusat Riset Perikanan adalah Indonesian Aquaculture Journal merupakan jurnal ilmiah berbahasa Inggris, terbit pertama kali pada tahun 2006, dengan kala terbit dua kali dalam setahun pada tahun 2009 mendapatkan akreditasi A hingga saat ini. Indonesian Aquaculture Journal menerima naskah atau artikel di bidang akuakultur berbagai akademisi dan peneliti secara nasional baik penelitian yang ditulis secara individu maupun berkolaborasi

Kolaborasi dalam penelitian menghasilkan karya ilmiah yang lebih lengkap dan bermutu, dikarenakan pemecahan masalah dilakukan secara bekerjasama berdasarkan kepakaran masing masing peneliti dalam penelitian tersebut, disamping itu keuntungan kolaborasi bagi peneliti (Prasetyadi, 2014) adalah :

1. Transfer pengetahuan dan keahlian.

2. Pertukaran ide dari berbagai ilmu yang akan menambah wawasan dan perspektif baru seseorang yang dapat memotivasi kreativitas.

3. Membuka kesempatan persahabatan intelektual.

\section{Peningkatan produktivitas.}

Peningkatan produktivitas peneliti dapat diukur dari sering dan banyaknya penulis tersebut dalam menghasilkan karya ilmiah yang dipublikasikan baik secara kolaborasi maupun individu. Pengukuran tingkat kolaborasi dan produktifitas dapat di evaluasi melalui penerapan bibliometrik, berdasar uraian diatas penulis tertarik untuk mengkaji kolaborasi dan produktivitas Indonesian Aquaculture Journal agar dapat diketahui kolaborasi pola keperangan, pola penerbitan dalam artikel dan tingkat produktivitas penulis pada Indonesian Aquaculture Journal 2011-2015

\section{TINJAUAN PUSTAKA}

\section{Evaluasi Kolaborasi}

Pengertian evaluasi bersumber dari kamus Oxford Advanced Leaner's Dictionary of Current English evaluasi adalah to find out, decide the amount or value yang artinya suatu upaya untuk menentukan nilai atau jumlah (Gustinasari, 2012). Sedangkan kolaborasi adalah terjemahan dari kata collaboration yang artinya kerjasama antara lebih dari satu orang atau lebih dari satu lembaga dalam sebuah kegiatan, baik kegiatan penelitian maupun pendidikan. Kolaborasi pengarang dalam jurnal ilmiah dilakukan apabila penelitian dalam jurnal ilmiah tersebut tidak dapat dilakukan secara individu sehingga memerlukan kerjasama peneliti lain untuk berkontribusi dalam penelitiannnya sehingga didapatkan hasil karya ilmiah yang berkualitas (Sulistyo-Basuki, 1990).

Kajian kolaborasi digunakan untuk mengetahui produktivitas penulis dan menghitung tingkat kolaborasi. Pendekatan lainnya digunakan untuk membandingkan tingkat kolaborasi antar lembaga dan antar disiplin ilmu dalam suatu negara serta kondisi yang melatar belakangi penulis dalam melakukan kolaborasi (Anom, 2012).

Dalam mengevaluasi kolaborasi digunakan metode deskriptif dengan pendekatan bibliometrik menggunakan rumus Subramayan untuk menghitung tingkat kolaborasi dan menggambarkan tentang kepakaran dari objek penelitian. Dengan demikian dapat disimpulkan evaluasi kolaborasi merupakan pengukuran atau penilaian agar dapat diketahui tingginya tingkat kolaborasi dan produktivitas pengarang dalam suatu karya ilmiah

\section{Jurnal Ilmiah}

Jurnal ilmiah merupakan salah satu contoh terbitan berkala atau berseri, menurut Rifai (2001), jurnal adalah terbitan berkala yang berbentuk pamflet berseri berisi bahan yang sangat diminati orang saat diterbitkan. Sedangkan menurut Handbook for AACR2 dalam Siregar (2002) "A serial definition, is a publication, is a publication in any medium issued in successive parts bearing numerical or cronogical designation and intended to be continued indefinitely." definisi diatas menyebutkan bahwa terbitan berseri atau serial adalah publikasi yang diterbitkan berturutturut, bagian demi bagian, biasanya dengan jarak 
penerbitan yang tetap dan dimaksudkan untuk terbit terus menerus tanpa batas waktu tertentu.

Jurnal ilmiah memuat kumpulan artikel yang diterbitkan secara berkala, dengan penulis para ilmuwan atau peneliti untuk melaporkan hasil-hasil penelitian terbarunya, sebagaimana Lasa (1994) menyatakan ciri atau karakteristik terbitan berseri yang membedakan dengan publikasi perpustakaan lainnya adalah:

1. Dalam satu kali terbit memuat beberapa tulisan yang ditulis oleh beberapa orang dengan topik dan gaya bahasa yang berbeda.

2. Artikel atau tulisan pada umumnya tidak terlalu panjang sebagaimana pada buku teks.

3. Menyampaikan berita, peristiwa, penemuan dan ide baru atau sesuatu yang dianggap menarik perhatian masyarakat pada umumnya.

4. Dikelola oleh sekelompok orang, yang kemudian membentuk perkumpulan, organisasi maupun susunan redaksi.

5. Merupakan bentuk arsip ilmiah yang diketahui oleh masyarakat umum.

6. Terbit terus menerus dengan memiliki kala, waktu, frekuensi terbit tertentu.

Pusat Riset Perikanan sebagai lembaga penelitian dibawah Kementerian Kelautan telah menerbitkan 10 terbitan karya ilmiah, yang terdiri 7 terbitan yang terakreditasi yaitu Jurnal Riset Akuakultur, Jurnal Penelitian Perikanan Indonesia, Indonesian Aquaculture Journal, Indonesian Fisheries Research Journal, Media Akuakultur. Bawal Widya Riset Perikanan Tangkap, Jurnal Kebijakan Perikanan Indonesia. Dan yang belum terakreditasi adalah : Teknik Litkayasa Sumber Daya dan Penangkapan, Buletin Teknik Litkayasa Akuakultur dan Buletin dan Prosiding Forum Inovasi Teknologi Akuakultur

\section{METODE PENELITIAN}

Penelitian ini dilakukan dengan menggunaan metode desriptif menggunakan data Indonesian Aquaculture Journal selama lima tahun yaitu tahun 2011-2015. Peneltian ini dikelompokkan berdasarkan peringkat produktivitas penulis, pola kolaborasi dan perbandingan penulis peringkat produktivitas dan peringkat kolaborasi dengan pengolahan data menggunakan exel 2010

Analisa Data Metode bibliometrik perhitungan yang digunakan untuk menghitung tingkat kolaborasi antar penulis adalah dengan metode Subramayan (1983) dengan rumus:

$$
\mathrm{C}=\frac{\mathrm{Nm}}{(\mathrm{Nm}+\mathrm{Ns}}
$$

Keterangan:

$\mathrm{C}=$ tingkat kolaborasi

$\mathrm{Nm}=$ total hasil penelitian yang dilakukan secara kolaborasi

$\mathrm{Ns}=$ total hasil penelitian yang dilakukan secara individu

Jika nilai $C=0$, hal ini menunjukkan hasil penelitian pada bidang tersebut seluruhnya dilakukan secara individual. Apabila nilai C berkisar $0<0,50$ maka dapat disimpulkan bahwa hasil penelitian lebih banyak dilakukan secara individual dibandingkan dengan cara kolaborasi dan jika nilai $C>0,50$ maka penelitian lebih banyak dilakukan secara kolaborasi. Apabila nilai $\mathrm{C}=1$ maka hasil penelitian seluruhnya dilakukan secara kolaborasi.

\section{HASIL DAN PEMBAHASAN}

\section{Jumlah Artikel}

Jumlah Artikel yang dimuat dalam Indonesian Aquaculture Journal tahun 2011-2015, dapat dilihat pada tabel 1 .

\begin{tabular}{|c|c|c|c|}
\hline \multirow{2}{*}{ No. } & \multicolumn{2}{|c|}{ Tahun dan Volume } & \multirow{2}{*}{ Jumlah } \\
\cline { 2 - 3 } & Tahun & Volume & Artikel \\
\hline 1 & 2011 & 6.1 & 10 \\
2 & 2011 & 6.2 & 10 \\
3 & 2012 & 7.1 & 10 \\
4 & 2012 & 7.2 & 10 \\
5 & 2013 & 8.1 & 10 \\
6 & 2013 & 8.2 & 10 \\
7 & 2014 & 9.1 & 10 \\
8 & 2014 & 9.2 & 10 \\
9 & 2015 & 10.1 & 10 \\
10 & 2015 & 10.2 & 10 \\
\hline \multicolumn{3}{|c|}{ Jumlah } & 100 \\
\hline
\end{tabular}

Pada tabel 1 memperlihatkan jumlah artkel pada Indonesian Aquaculture Journal selama kurun waktu 2011 - 2015 telah memuat 100 artikel

\subsection{Rekapitulasi penulis dalam pola penerbitan artikel dapat dilihat pada tabel 2, sebagai berikut :}


Tabel 2: Rekapitulasi kolaborasi penulis dalam penerbitan artikel tahun 2011-2015

\begin{tabular}{|c|c|c|c|c|c|c|c|}
\hline \multirow{2}{*}{$\begin{array}{c}\text { Pola } \\
\text { Kepengarang }\end{array}$} & \multicolumn{5}{|c|}{ Tahun Pola Penerbitan Artikel } & \multirow{2}{*}{$\begin{array}{l}\text { Jumlah } \\
\text { Artike I }\end{array}$} & \multirow{2}{*}{$\begin{array}{c}\text { Jumlah } \\
\text { Artikel } \\
\text { Kolaborasi }\end{array}$} \\
\hline & 2011 & 2012 & 2013 & 2014 & 2015 & & \\
\hline 1 Penulis & 2 & 1 & 4 & 1 & 0 & 8 & 0 \\
\hline 2 Penulis & 6 & 5 & 3 & 7 & 3 & 24 & 24 \\
\hline 3 Penulis & 5 & 6 & 9 & 3 & 8 & 31 & 31 \\
\hline 4 Penulis & 3 & 5 & 2 & 1 & 5 & 16 & 16 \\
\hline 5 Penulis & 2 & 2 & 2 & 4 & 4 & 14 & 14 \\
\hline 6 Penulis & 1 & 1 & 0 & 3 & 0 & 5 & 5 \\
\hline 7 Penulis & 0 & 0 & 0 & 1 & 0 & 1 & 1 \\
\hline 8 Penulis & 1 & 0 & 0 & 0 & 0 & 1 & 1 \\
\hline Jumlah & 20 & 20 & 20 & 20 & 20 & 100 & 92 \\
\hline
\end{tabular}

Pada Tabel 2 memperlihatkan kolaborasi penulis dalam penerbitan artikel dari tahun 2011 2015, yaitu penulis kolaborasi sebanyak 92 artikel dengan rician : 2 penulis sebanyak 8 artikel, 3 penulis 31 artikel, 4 penulis 16 artikel, 5 penulis 14 artikel, 6 penulis 5 artikel, 7 penulis 8 artikel 1 artikel dan 8 penulis 1 artikel dan penulis individu sebanyak 8 artikel

\section{Rekapitulasi Penulis dalam Pola Kepengarangan}

Rekapitulasi kolaborasi penulis dalam pola kepengarangan dapat dilihat pada tabel 3 sebagai berikut :
Pada Tabel 3. memperlihatkan kolaborasi penulis dalam kepengarangan tahun 2011 - 2015 berjumlah 320 pengarang dimana pada tahun 2011 yang terlibat dalam penulisan sebanyak 63 pengarang, tahun 2012 sebanyak 64 pengarang, tahun 2013 sebanyak 51 pengarang, 2014 sebanyak 72 pengarang dan tahun 2015 sebanyak 70 pengarang.

Daftar peringkat penulis paling Produktif pada Indonesian Aquaculture Journal periode 2011- 2015 dapat dilihat pada tabel 4. sebagai berikut :

Tabel 3: Rekapitulasi kolaborasi penulis dalam kepengarangan tahun 2011-2015

\begin{tabular}{|c|c|c|c|c|c|c|c|c|c|c|}
\hline \multirow{2}{*}{ Tahun } & \multicolumn{8}{|c|}{ Pola Ke pe ngarangan } & \multirow{2}{*}{$\begin{array}{c}\text { Jumlah } \\
\text { Pengarang }\end{array}$} & \multirow{2}{*}{$\begin{array}{c}\text { Jumlah } \\
\text { Pengarang } \\
\text { Koloborasi } \\
\end{array}$} \\
\hline & 1 & 2 & 3 & 4 & 5 & 6 & 7 & 8 & & \\
\hline 2011 & 2 & 12 & 15 & 12 & 10 & 6 & 0 & 8 & 65 & 63 \\
\hline 2012 & 1 & 10 & 18 & 20 & 10 & 6 & 0 & 0 & 65 & 64 \\
\hline 2013 & 4 & 6 & 27 & 8 & 10 & 0 & 0 & 0 & 55 & 51 \\
\hline 2014 & 1 & 14 & 9 & 4 & 20 & 18 & 7 & 0 & 73 & 72 \\
\hline 2015 & 0 & 6 & 24 & 20 & 20 & 0 & 0 & 0 & 70 & 70 \\
\hline Jumlah & 8 & 48 & 93 & 64 & 70 & 30 & 7 & 8 & 328 & 320 \\
\hline
\end{tabular}


Tabel 4. Daftar penulis paling Produktif pada Indonesian Aquaculture Journal tahun 2011-2015

\begin{tabular}{|c|l|c|c|c|c|c|c|}
\hline No. & \multicolumn{1}{|c|}{ Nama } & $\mathbf{2 0 1 1}$ & $\mathbf{2 0 1 2}$ & $\mathbf{2 0 1 3}$ & $\mathbf{2 0 1 4}$ & $\mathbf{2 0 1 5}$ & Jumlah \\
\hline 1 & Imron Imron & 1 & 2 & 3 & 1 & 4 & 11 \\
\hline 2 & Ketut Mahardika & 1 & 4 & 3 & 1 & 1 & 10 \\
\hline 3 & Huria Marnis & 0 & 1 & 1 & 2 & 4 & 8 \\
\hline 4 & Indah Mastuti & 0 & 4 & 3 & 0 & 1 & 8 \\
\hline 5 & Bambang Is wanto & 0 & 1 & 1 & 1 & 4 & 7 \\
\hline 6 & Rommy Suprapto & 0 & 0 & 2 & 1 & 4 & 7 \\
\hline 7 & I Nyoman Radiarta & 2 & 1 & 1 & 2 & 0 & 6 \\
\hline 8 & Andi Parenrengi & 0 & 2 & 0 & 2 & 2 & 6 \\
\hline 9 & R.R. Sri Pudji Sinarni Dewi & 0 & 3 & 0 & 2 & 1 & 6 \\
\hline
\end{tabular}

Pada Tabel 4. Memperlihatkan daftar peringkat 2 tertinggi penulis paling produktif dalam penulisan periode 5 tahun penelitian. Dalam tabel tercatat bahwa penulis yang produktif yaitu Imron (11 artikel) Ketut Mahardika (10 artikel)
4.5. Daftar Perbandingan Penulis Peringkat Produktivitas dan Peringkat Kolaborasi Indonesian Aquaculture Journal 20112015, dapat dilihat pada tabel 5. sebagai berikut:

Tabel 5. Daftar Perbandingan Penulis Peringkat Produktivitas dan Peringkat Kolaborasi Indonesian Aquaculture Journal 2011-2015

\begin{tabular}{|c|c|c|c|c|}
\hline No. & Nama & NS & NM & C \\
\hline 1 & Asda Laining & 1 & 0 & 0,00 \\
\hline 2 & Estu Nugroho & 1 & 0 & 0,00 \\
\hline 3 & Ludi Parwadani Aji & 1 & 0 & 0,00 \\
\hline 4 & Ofri Johan & 1 & 0 & 0,00 \\
\hline 5 & Wa Iba & 1 & 0 & 0,00 \\
\hline 6 & I Nyoman Radiarta & 2 & 4 & 0,67 \\
\hline 7 & Ketut Mahardika & 1 & 9 & 0,90 \\
\hline 8 & Achmad Sudradjat & 0 & 1 & 1,00 \\
\hline 9 & Adam Robisalmi & 0 & 3 & 1,00 \\
\hline 10 & Adi Basukriadi & 0 & 1 & 1,00 \\
\hline 11 & Afifah Nasukha & 0 & 1 & 1,00 \\
\hline 12 & Agus Priyadi & 0 & 2 & 1,00 \\
\hline 13 & Agus Priyono & 0 & 1 & 1,00 \\
\hline 14 & Ahmad Muzaki & 0 & 5 & 1,00 \\
\hline 15 & Akhmad Mustafa & 0 & 4 & 1,00 \\
\hline 16 & $\begin{array}{l}\text { Alien Karlina } \\
\text { Larasati }\end{array}$ & 0 & 1 & 1,00 \\
\hline 17 & Alimuddin Alimuddin & 0 & 2 & 1,00 \\
\hline 18 & Almas Khurshid & 0 & 1 & 1,00 \\
\hline 19 & Anang Hari Kristanto & 0 & 2 & 1,00 \\
\hline 20 & Andi Gusti Tantu & 0 & 1 & 1,00 \\
\hline 21 & $\begin{array}{l}\text { Andi Indra Jaya } \\
\text { Asaad }\end{array}$ & 0 & 2 & 1,00 \\
\hline 22 & Andi Parenrengi & 0 & 6 & 1,00 \\
\hline 23 & Andi Tenriulo & 0 & 4 & 1,00 \\
\hline 24 & Andreas Kunzmann & 0 & 2 & 1,00 \\
\hline
\end{tabular}

\begin{tabular}{|c|c|c|c|c|}
\hline No. & Nama & NS & NM & C \\
\hline 25 & $\begin{array}{l}\text { Angela Mariana } \\
\text { Lusiastuti }\end{array}$ & 0 & 1 & 1,00 \\
\hline 26 & $\begin{array}{l}\text { Anjang Bangun } \\
\text { Prasetio }\end{array}$ & 0 & 1 & 1,00 \\
\hline 27 & Apri I & 0 & 1 & 1,00 \\
\hline 28 & Arief Taslihan & 0 & 1 & 1,00 \\
\hline 29 & Arifuddin Arifuddin & 0 & 1 & 1,00 \\
\hline 30 & Asda Laining & 0 & 5 & 1,00 \\
\hline 31 & Asep Permana & 0 & 2 & 1,00 \\
\hline 32 & Ayi Santika & 0 & 1 & 1,00 \\
\hline 33 & Aziz Ahmad & 0 & 1 & 1,00 \\
\hline 34 & $\begin{array}{l}\text { Bambang Djadmo } \\
\text { Kertonegoro }\end{array}$ & 0 & 1 & 1,00 \\
\hline 35 & Bambang Gunadi & 0 & 1 & 1,00 \\
\hline 36 & Bambang Iswanto & 0 & 7 & 1,00 \\
\hline 37 & Bambang Sumiarto & 0 & 1 & 1,00 \\
\hline 38 & Bambang Susanto & 0 & 1 & 1,00 \\
\hline 39 & Brata Pantjara & 0 & 2 & 1,00 \\
\hline 40 & $\begin{array}{l}\text { Bunga Rante } \\
\text { Tampangallo }\end{array}$ & 0 & 1 & 1,00 \\
\hline 41 & Byung Hwa Min & 0 & 1 & 1,00 \\
\hline 42 & Dadan Sunandar & 0 & 1 & 1,00 \\
\hline 43 & David Smith & 0 & 1 & 1,00 \\
\hline 44 & Dedi Jusadi & 0 & 1 & 1,00 \\
\hline 45 & Dewi Puji Lestari & 0 & 1 & 1,00 \\
\hline 46 & Dewi Syahidah & 0 & 1 & 1,00 \\
\hline
\end{tabular}




\begin{tabular}{|c|c|c|c|c|}
\hline No. & Nama & NS & NM & C \\
\hline 47 & Didik Ariyanto & 0 & 3 & 1,00 \\
\hline 48 & $\begin{array}{l}\text { Dietriech Geoffrey } \\
\text { Bengen }\end{array}$ & 0 & 1 & 1,00 \\
\hline 49 & Dikry Novel Shatrie & 0 & 1 & 1,00 \\
\hline 50 & $\begin{array}{l}\text { Dinar Tri } \\
\text { Soelistyawati }\end{array}$ & 0 & 1 & 1,00 \\
\hline 51 & Eddy Supriyono & 0 & 1 & 1,00 \\
\hline 52 & Eko Hanudin & 0 & 1 & 1,00 \\
\hline 53 & Emma Suryati & 0 & 2 & 1,00 \\
\hline 54 & Emmanuel Paradis & 0 & 1 & 1,00 \\
\hline 55 & Enang Harris & 0 & 1 & 1,00 \\
\hline 56 & $\begin{array}{l}\text { Endang } \\
\text { Susianingsih }\end{array}$ & 0 & 2 & 1,00 \\
\hline 57 & $\begin{array}{l}\text { Endhay Kusnendar } \\
\text { Kontara }\end{array}$ & 0 & 1 & 1,00 \\
\hline 58 & Eni Kusrini & 0 & 1 & 1,00 \\
\hline 59 & Erfan Andi Hendrajat & 0 & 1 & 1,00 \\
\hline 60 & Eri Setiadi & 0 & 2 & 1,00 \\
\hline 61 & Erlania Erlania & 0 & 2 & 1,00 \\
\hline 62 & Erna Ratnawati & 0 & 2 & 1,00 \\
\hline 63 & Evi Tahapari & 0 & 3 & 1,00 \\
\hline 64 & Fahrudin Fahrudin & 0 & 1 & 1,00 \\
\hline 65 & Farida Mohamad & 0 & 1 & 1,00 \\
\hline 66 & George N Nishihara & 0 & 1 & 1,00 \\
\hline 67 & Habsah Mohamad & 0 & 2 & 1,00 \\
\hline 68 & Hadiyanto Hadiyanto & 0 & 1 & 1,00 \\
\hline 69 & Harry Wuwungan & 0 & 1 & 1,00 \\
\hline 70 & Haryanti Haryanti & 0 & 3 & 1,00 \\
\hline 71 & Hatim Albasri & 0 & 1 & 1,00 \\
\hline 72 & $\begin{array}{l}\text { Hirmawan Tirta } \\
\text { Yudha }\end{array}$ & 0 & 2 & 1,00 \\
\hline 73 & Huria Marnis & 0 & 8 & 1,00 \\
\hline 74 & I Ahmad & 0 & 1 & 1,00 \\
\hline 75 & $\begin{array}{l}\text { I Gusti Ngurah } \\
\text { Permana }\end{array}$ & 0 & 2 & 1,00 \\
\hline 76 & $\begin{array}{l}\text { I Nyoman Adiasmara } \\
\text { Giri }\end{array}$ & 0 & 1 & 1,00 \\
\hline 77 & I Wayan Subamia & 0 & 2 & 1,00 \\
\hline 78 & Ibnu Rusdi & 0 & 1 & 1,00 \\
\hline 79 & $\begin{array}{l}\text { Ida Komang } \\
\text { Wardana }\end{array}$ & 0 & 4 & 1,00 \\
\hline 80 & Ikhsan Khasani & 0 & 1 & 1,00 \\
\hline 81 & Imam Taufik & 0 & 1 & 1,00 \\
\hline 82 & Imron Imron & 0 & 11 & 1,00 \\
\hline 83 & $\begin{array}{l}\text { Ince Ayu Khairana } \\
\text { Kadriah }\end{array}$ & 0 & 1 & 1,00 \\
\hline 84 & Indah Mastuti & 0 & 8 & 1,00 \\
\hline 85 & $\begin{array}{l}\text { Indaryulianto } \\
\text { Indaryulianto }\end{array}$ & 0 & 1 & 1,00 \\
\hline
\end{tabular}

\begin{tabular}{|c|c|c|c|c|}
\hline No. & Nama & NS & NM & C \\
\hline 86 & Irsyaphiani Insan & 0 & 1 & 1,00 \\
\hline 87 & Irvan Faizal & 0 & 1 & 1,00 \\
\hline 88 & Isti Koesharyani & 0 & 4 & 1,00 \\
\hline 89 & Jacques Slembrouck & 0 & 1 & 1,00 \\
\hline 90 & Jadmiko Darmawan & 0 & 1 & 1,00 \\
\hline 91 & Jenny-Ann Torribio & 0 & 1 & 1,00 \\
\hline 92 & $\begin{array}{l}\text { John Harianto } \\
\text { Hutapea }\end{array}$ & 0 & 2 & 1,00 \\
\hline 93 & Jojo Subagja & 0 & 1 & 1,00 \\
\hline 94 & Joni Haryadi & 0 & 2 & 1,00 \\
\hline 95 & $\begin{array}{l}\text { Kamiso Handoyo } \\
\text { Nitimulyo }\end{array}$ & 0 & 2 & 1,00 \\
\hline 96 & Ketut Sugama & 0 & 3 & 1,00 \\
\hline 97 & Ki Tae Kim, & 0 & 1 & 1,00 \\
\hline 98 & $\begin{array}{l}\text { Komar } \\
\text { Sumantadinata }\end{array}$ & 0 & 1 & 1,00 \\
\hline 99 & Kurniasih Kurniasih & 0 & 2 & 1,00 \\
\hline 100 & Laurent Pouyaud & 0 & 1 & 1,00 \\
\hline 101 & Leigh Owens & 0 & 1 & 1,00 \\
\hline 102 & Lidemen Lidemen & 0 & 3 & 1,00 \\
\hline 103 & Lies Setijaningsih & 0 & 1 & 1,00 \\
\hline 104 & Lila Gardenia & 0 & 4 & 1,00 \\
\hline 105 & Lisa Fajar Indriana & 0 & 1 & 1,00 \\
\hline 106 & Luqman Saleh & 0 & 1 & 1,00 \\
\hline 107 & Manabu Ishikawa & 0 & 1 & 1,00 \\
\hline 108 & Masaaki Wada & 0 & 1 & 1,00 \\
\hline 109 & Masahiro Yasuda & 0 & 1 & 1,00 \\
\hline 110 & $\begin{array}{l}\text { Media Fitri Isma } \\
\text { Nugraha }\end{array}$ & 0 & 1 & 1,00 \\
\hline 111 & Melta Rini Fahmi & 0 & 1 & 1,00 \\
\hline 112 & Michael Sweet & 0 & 1 & 1,00 \\
\hline 113 & Mubinun Mubinun & 0 & 1 & 1,00 \\
\hline 114 & Mufti Petala Patria & 0 & 1 & 1,00 \\
\hline 115 & $\begin{array}{l}\text { Muhadiono } \\
\text { Muhadiono } \\
\end{array}$ & 0 & 1 & 1,00 \\
\hline 116 & $\begin{array}{l}\text { Muhammad Ikbal } \\
\text { Illijas }\end{array}$ & 0 & 1 & 1,00 \\
\hline 117 & $\begin{array}{l}\text { Muhammad Nur } \\
\text { Syafaat }\end{array}$ & 0 & 1 & 1,00 \\
\hline 118 & $\begin{array}{l}\text { Muharijadi } \\
\text { Atmomarsono }\end{array}$ & 0 & 3 & 1,00 \\
\hline 119 & Munti Yuhana & 0 & 1 & 1,00 \\
\hline 120 & Muslikhin Muslikhin & 0 & 1 & 1,00 \\
\hline 121 & Muslimin Muslimin & 0 & 1 & 1,00 \\
\hline 122 & Najiah Musa & 0 & 2 & 1,00 \\
\hline 123 & $\begin{array}{l}\text { Narita Syawalia } \\
\text { Ridzwan }\end{array}$ & 0 & 3 & 1,00 \\
\hline 124 & Neviaty Putri Zamani & 0 & 1 & 1,00 \\
\hline 125 & $\begin{array}{l}\text { Ni Wayan Widya } \\
\text { Astuti }\end{array}$ & 0 & 1 & 1,00 \\
\hline
\end{tabular}




\begin{tabular}{|c|c|c|c|c|}
\hline No. & Nama & NS & NM & C \\
\hline 126 & Nina Meilisza & 0 & 2 & 1,00 \\
\hline 127 & Noraznawati Ismail & 0 & 1 & 1,00 \\
\hline 128 & Nuddin Harahab & 0 & 1 & 1,00 \\
\hline 129 & Nunak Nafiqoh & 0 & 2 & 1,00 \\
\hline 130 & Nunuk Listiyowati & 0 & 3 & 1,00 \\
\hline 131 & $\begin{array}{l}\text { Nur Bambang Priyo } \\
\text { Utomo }\end{array}$ & 0 & 1 & 1,00 \\
\hline 132 & Nurbaya Nurbaya & 0 & 1 & 1,00 \\
\hline 133 & \begin{tabular}{|l|} 
Nurhidayah \\
Nurhidayah \\
\end{tabular} & 0 & 1 & 1,00 \\
\hline 134 & Odang Carman & 0 & 1 & 1,00 \\
\hline 135 & Ofri Johan & 0 & 1 & 1,00 \\
\hline 136 & Patrick Berrebi & 0 & 1 & 1,00 \\
\hline 137 & Poh-Shing Chang & 0 & 2 & 1,00 \\
\hline 138 & Priadi Setyawan & 0 & 2 & 1,00 \\
\hline 139 & Rachman Syah & 0 & 2 & 1,00 \\
\hline 140 & $\begin{array}{l}\text { Raden Roro Sri } \\
\text { Pudji Sinarni Dewi }\end{array}$ & 0 & 6 & 1,00 \\
\hline 141 & Regina Melianawati & 0 & 1 & 1,00 \\
\hline 142 & Rehana Kausar & 0 & 1 & 1,00 \\
\hline 143 & Retno Andamari & 0 & 1 & 1,00 \\
\hline 144 & Riani Rahmawati & 0 & 1 & 1,00 \\
\hline 145 & Richard Callinan & 0 & 1 & 1,00 \\
\hline 146 & Rina Hirnawati & 0 & 1 & 1,00 \\
\hline 147 & Riza Priyatna & 0 & 1 & 1,00 \\
\hline 148 & Rommy Suprapto & 0 & 7 & 1,00 \\
\hline 149 & Rosmiati Rosmiati & 0 & 4 & 1,00 \\
\hline 150 & \begin{tabular}{|l|} 
Ruby Vidia \\
Kusumah \\
\end{tabular} & 0 & 1 & 1,00 \\
\hline 151 & Rudhy Gustiano & 0 & 1 & 1,00 \\
\hline 152 & Ryuta Terada & 0 & 1 & 1,00 \\
\hline 153 & Saberina Hasibuan & 0 & 1 & 1,00 \\
\hline 154 & Samuel Lante & 0 & 1 & 1,00 \\
\hline 155 & $\begin{array}{l}\text { Sari Budi Moria } \\
\text { Sembiring }\end{array}$ & 0 & 3 & 1,00 \\
\hline 156 & Sebastian Kaspers & 0 & 1 & 1,00 \\
\hline 157 & Shunsuke Koshio & 0 & 1 & 1,00 \\
\hline 158 & Siti Murniasih & 0 & 1 & 1,00 \\
\hline 159 & $\begin{array}{l}\text { Soemarno } \\
\text { Soemarno } \\
\end{array}$ & 0 & 1 & 1,00 \\
\hline 160 & Sophia Sagala & 0 & 1 & 1,00 \\
\hline 161 & Sudarto Sudarto & 0 & 2 & 1,00 \\
\hline 162 & Sudewi Sudewi & 0 & 1 & 1,00 \\
\hline 163 & $\begin{array}{l}\text { Suharsono } \\
\text { Suharsono }\end{array}$ & 0 & 1 & 1,00 \\
\hline 164 & Sukenda Sukenda & 0 & 2 & 1,00 \\
\hline 165 & Sulasy Rohmy & 0 & 1 & 1,00 \\
\hline
\end{tabular}

\begin{tabular}{|c|c|c|c|c|}
\hline No. & Nama & NS & NM & C \\
\hline 166 & Supii & 0 & 1 & 1,00 \\
\hline 167 & Sutrisno Sutrisno & 0 & 1 & 1,00 \\
\hline 168 & Syamsul Alam Ali & 0 & 1 & 1,00 \\
\hline 169 & Tatag Budiardi & 0 & 1 & 1,00 \\
\hline 170 & Tatam Sutarmat & 0 & 1 & 1,00 \\
\hline 171 & Tatik Mufidah & 0 & 1 & 1,00 \\
\hline 172 & Tb. Haeru Rahayu & 0 & 1 & 1,00 \\
\hline 173 & $\begin{array}{l}\text { Tengku Sifzizul } \\
\text { Tengku Muhammad }\end{array}$ & 0 & 2 & 1,00 \\
\hline 174 & Teruo Miyazaki & 0 & 1 & 1,00 \\
\hline 175 & Titiek Aslianti & 0 & 1 & 1,00 \\
\hline 176 & Triyanto Triyanto & 0 & 1 & 1,00 \\
\hline 177 & Usman Usman & 0 & 1 & 1,00 \\
\hline 178 & $\begin{array}{l}\text { Vitas Atmadi } \\
\text { Prakoso }\end{array}$ & 0 & 2 & 1,00 \\
\hline 179 & Wahyu Pamungkas & 0 & 2 & 1,00 \\
\hline 180 & Wahyu Purbowasito & 0 & 1 & 1,00 \\
\hline 181 & Wahyuni Wahyuni & 0 & 1 & 1,00 \\
\hline 182 & Wartono Hadie & 0 & 1 & 1,00 \\
\hline 183 & Wawan Andriyanto & 0 & 1 & 1,00 \\
\hline 184 & Wisnu Nurcahyo & 0 & 1 & 1,00 \\
\hline 185 & $\begin{array}{l}\text { Yasmina Nirmala } \\
\text { Asih }\end{array}$ & 0 & 1 & 1,00 \\
\hline 186 & Young Jin Chang & 0 & 2 & 1,00 \\
\hline 187 & Yu-Chi Wang & 0 & 2 & 1,00 \\
\hline 188 & Yutaka Itabashi & 0 & 1 & 1,00 \\
\hline 189 & Zafran Zafran & 0 & 1 & 1,00 \\
\hline & Jumlah & 8 & 320 & 0,98 \\
\hline
\end{tabular}

Tabel 5. Memperlihatkan perbandingan antara peringkat produktivitas dan peringkat kolaborasi dalam Indonesian Aquaculture Journal tahun 2011-2015 berjumlah 189 nama penulis. Berdarkan rumus Subramanya (1983) dapat diketahui jumlah $\mathrm{C}=0$ sebanyak 5 penulis, $0<$ $C<0,5$ sebanyak 0 penulis, $C=0,5$ sebanyak 2 penulis, $0,5<C<1$ sebanyak 0 penulis dan $C=1$ sebanyak 181 penulis dengan rata-rata kolaborasi sebesar 0,98.

Berdasarkan Tabel 5 nilai rata-rata tingkat kolaborasi antara kedua parameter tersebut menunjukkan peringkat yang sangat tinggi sebesar 0,98 . Artinya semakin sering peneliti berkolaborasi maka kualitas dan kualitas dalam Indonesian Aquaculture Journal 2011-2015 semakin tinggi kualitas penelitian yang dihasilkan. 


\section{KESIMPULAN}

Berdasarkan hasil analisis dan pembahasan aspek produktivitas dan tingkat kolaborasi penulis, maka dapat dambil kesimpulan sebagai berikut:

1. Jumlah artikel pada Indonesian Aquaculture Journal 2011-2015 sebanyak 100 artikel

2. Selama kurun waktu tahun $2011-2015$ sebanyak 8 artikel dilakukan penulisan secara individual dan 92 artikel penulisan dilakukan secara kolaborasi, adapun untuk pola kepengarangan secara kolaborasi sebanyak 320 dan secara individu sebanyak 8

3. Penulis yang paling produktif yang termuat dalam Indonesian Aquaculture Journal 20112015 adalah Imron (11 artikel) dan diikuti oleh Ketut Mahardika (10 artikel)

4. Kajian ini juga menunjukkan bahwa tingkat kolaborasi penulis dalam penulisan artikel selama 2011-2015 memiliki rata-rata kolaborasi yang cukup tinggi, yakni sebesar 0,98 . Angka ini merupakan kriteria positif untuk menilai semakin tingginya kualitas penelitian yang dihasilkan

\section{DAFTAR PUSTAKA}

Anom, S. 2012. Kolaborasi Peneliti Bidang Sains: Sebuah Kajian Bibliometrik Pada Makara Seri Sains dan jurnal Matematika dan Sains. Depok: Universitas Indonesia

Basuki, Sulistyo. 1990. Kolaborasi Pengarang Sebuah Kajian Bibliometrik. Majalah Ikatan Pustakawan Indonesia, 12: 12-18.
Habibillah, AD, 2010.b Evaluasi Pelaksanaan Program Dana Penguatan Modal (DPM APBN TA 2006) Melalui Mekanisme Pinjaman Bagi Pembudidaya Ikan Skala Kecil Di Kota Metro, Thesis : Universitasi Indonesia

Lasa, HS. 1994. Pengelolaan terbitan berkala, penerbit kanisius, Yogyakarta

Online Journal System Pusriskan, 2016. About Indonesian Aquaculture Journal, Http:// ejournal- balitbang.kkp.go.id/index.php/iaj / diakses 16 Juni 2017

Prasetyadi, A dan D.W. Ari Nugroho , 2014. Visi Pustaka Vol. 16 No. 1 - April 2014

Rifai, MA. 2001. Pegangan Gaya Penulisan, Penyuntingan, dan Penerbitan Karya IImiah Indonesia, Gadjah Mada University. Yogyakarta

Gustinasari, S. 2012. Pengertian Evaluasi, https://syafnigustinasari.wordpress. com/2012/01/07/pengertian-evaluasi I diakses 10 Juli 2017

Siregar, B. 2002. Pengembangan koleksi, Medan : Badan Perpustakaan dan Arsip Daerah Propinsi Sumut

Subramayan, K. 1983. Bibliometric studies ofresearch collaboration: a review. Journalof Information Science, 6: 33-38 